\title{
Open perseverance: the sensemaking narrative of startup entrepreneurs
}

Fran Morente
Fjmp.1984@gmail.com
University of Vic, Spain
Xavier Ferràs
Xavier.ferras@uvic.cat
University of Vic, Spain

\begin{abstract}
The irruption of startups and entrepreneurs has transformed the economic landscape. Entrepreneurs propose innovative business models that must progressively respond to the viability triad, the complex and uncertain process by which an idea becomes a product. Based on the theoretical and practical contributions of Dervin's sensemaking methodology, the objective of this study is to understand the narrative of entrepreneurs in their creation of meaning, identify the uncertainties, identify the practices used to address these uncertainties, and thus obtain a deep knowledge of the sensemaking mechanisms. The results of 43 interviews with entrepreneurs are presented in the form of a narrative composed of four stages and three major gaps, illustrating the practical ways in which entrepreneurs overcome uncertainty and create metastable sense.
\end{abstract}

Keywords: Innovation, creativity, startup, entrepreneur, sensemaking, viability triad, Brenda Dervin, narrative. 
Morente, F. \& Ferràs, X. (2018) Open perseverance: the sensemaking narrative of startup entrepreneurs. Journal of Business, Universidad del Pacífico (Lima, Peru) Vol.10(2): 2-23

\section{Introduction}

\section{Entrepreneurship}

The latest Digital Startup Ecosystem Overview (MWCB, 2018) provides illuminating information about the Spanish entrepreneurial ecosystem: there are 3,258 active startups, a $20 \%$ growth on 2016, with Barcelona and Madrid as the main hubs (34\% and $31 \%$, respectively); Spain has the third-highest number of entrepreneurs in Europe; around $80 \%$ of young persons between 20 and 30 years of age work for a startup; and in 2018, investment in the ecosystem reached 779.3 million euros, a record high. Far from being a passing phenomenon, with worldwide investment totaling 140 billion dollars in 2017 alone, and more than 300 associations, startups are changing the late-capitalist economy with unprecedented dynamism (Startup Genome, 2018). Steve Blank and Bob Dorf (2012) define a startup as a temporary organization in search of a scalable and repeatable business model. The startup, and its fundamental core - the entrepreneur are the beating heart of the third wave of the internet in which the irruption of social media sites and, since 2016, the pervasive connectivity and creativity of thousands of digital entrepreneurs have transformed the current economy into a complex and integrated network of innovative solutions (Case, 2017). In this third wave, startups, small, bold and nimble, rely on disruptive technologies in the race against time for sustained growth (Ries, 2011), their innovative approach throwing up many uncertainties along the way (Thiel \& Masters, 2014).

The spirited willingness of startups to explore technological applications and test new business opportunities has permeated our understanding of work (Mazzucato, 2018). In this context in which startups play such an important part, a new type of actor has emerged - the entrepreneur (Sarasvathy, 2008) - to challenge the old ways of doing business (Ries, 2011). The term entrepreneur - from the French entreprendre- was coined by Cantillon; the entrepreneur acquired labor and assets at a known cost to produce goods at uncertain prices. Thus, the entrepreneur took on risks by pursuing unknown profit margins (Peneder, 2009). Salhman et al. (1999), in the classic The Entrepreneurial Venture, complete the definition: as well as the risk assumed and the finite resources, the entrepreneur is characterized by a search for innovative opportunities. While some compete in overexploited markets (red oceans), entrepreneurs seek out new market spaces (blue oceans) with their innovative propositions: unchartered territories of competition, not yet explored conceptually or exploited commercially, that promise unknown growth and profit opportunities (Chan Kim \& Mauborgne, 2014). If an entrepreneur is unable to demonstrate the viability of their pioneering proposal in two years, they will perish (Blank \& Dorf, 2012); this, in the jargon, is known as "zero to one" (Thiel \& Masters, 2014). Therefore, our sample is composed of entrepreneurs who, through their startups, explore and attempt to launch their brand new business ideas.

In so doing the entrepreneurs go through the viability triad, which consists of (1) desirability (of the product); (2) feasibility (of the technology); and (3) sustainability (of the business model) (Hunsaker \& Douglas, 2017). This innovation process, in which entrepreneurs commit to maturing their initial idea, validating it progressively, and obtaining a product, is fraught with uncertainty in terms of expected outcomes, probabilities of success or failure, decision-making, lack of knowledge, and even the venture's short-term survival (Deakins \& Whitman, 2000). The process is, in a word, iterative: falsely linear, forward and backward, testing and developing, with small successes that lead to progress followed by major corrections that require steps back to right the course (Gaglio, 2011). Startup entrepreneurs face uncertainty throughout the entire process (Bessant \& Tidd, 2011), live in instability (Thiel \& Masters, 2014), and bear sole responsibility for overcoming pure contingency to generate new market value (Wickham, 2004). 
Uncertainty refers to the state of unknowing caused by the ambiguous, the imperfect, or the unknown in the information possessed (Geersbro \& Ritter, 2010), and for the entrepreneur, innovating equates to dissipating this uncertainty (Alter, 2013). As Porter (1980) points out, only those who manage uncertainty - by coping in unknown contexts and properly interpreting discontinuous signals - are able to triumph or even survive.

\section{Sensemaking}

This uncertainty should be met through the making of tacit and socially constructed sense (Weick, 1995). People have a natural inclination to respond to the stimulus, whether positive or negative, of uncertainty by organizing information and making sense (Dervin, 2008; Weick, Sutcliffe \& Obstfeld, 2005). Among scholars, one of the most accepted concepts with which to explain this response to uncertainty is the concept of sensemaking (Pitch, Loch \&y Meyer, 2002), whereby, in cycles of iteration and retrospective interpretation, individuals generate metastablity: sense that is stable at a given moment but in continuous transformation, making it reflexive and useful for specific situations (Weick, 1995; Dervin, 1992).

Dervin (1992) argues that sensemaking is fundamental for our lives; to live, it is necessary to generate order from a position of previous unknowing and ambiguity (Foreman-Wernet, 2003; Weick, 1995). These uncertain situations move us to make what Harvey Sacks (2006) calls inferences: compiling, collating, linking, and ordering scattered data fragments. When sense - equivalent to "meaning" and to "direction" - is possessed, the action of interacting with our environment becomes possible (Dervin \& Naumer, 2009; Dervin, 1992); to know is to act (Dervin \& Foreman-Wernet, 2012). Sensemaking is not an individual activity; on the contrary, when faced with complex situations during the construction process, individuals come together to look for plausible sense that gives them shared knowledge and enables reciprocal understanding (Maitlis, 2005; Dervin, 1992). However, the process of receiving signals, reflecting, interpreting, making sense and, in consequence, acting, is never linear; plagued with false and backward steps, mistakes and overlapping opinions, sensemaking is a process of constant reinterpretation, dialogue and action (Maitlis \& Christianson, 2014). The sensemaking process never stops (Devin \& Foreman-Wernet, 2012). The inferential reconstruction of fragments and the attribution of sense to complex situations based on non-linear social constructions assumes two characteristics that are appropriate for studying the way in which an idea becomes reality in the hands of an entrepreneur, since this process is not only uncertain and spiraled, but extremely social: no one innovates on their own (Alter, 2013).

The concept of sensemaking is usually associated with the work of Karl E. Weick, on organizations; and that of Brenda Dervin, on information science. However, the concept is not confined to these spheres; the mechanics of sensemaking have been widely applied to and explored in other studies of collectives or specific occurrences. Examples include school failure (Walls, 2017); information processing (Zhang \& Duohai, 2014); technology integration in hospitals (Kitzmiller et al., 2010); repatriation (Kelly \& Morley, 2011), decision-making (Choo, 2002); hierarchal restructuring (Bologun \& Johnson, 2004); organizational crises (Gephart, 1997); e-learning implementation at business schools (Sabino de Freitas \& Bandeira-de-Melho, 2012) and even military analysis (Attfield et al., 2015). The field of innovation is no exception, and there have been studies of sensemaking in temporary organizations; (Feldbrugge, 2014); the wool industry (Sneddon, 2008); and unk-unk detection (Segger Macri Russo et al. 2017) Moreover, the literature relating entrepreneurship and sensemaking has grown considerably, focusing on decision-making by entrepreneurs (Nouri \& Kafeshani, 2014); management of business failures and crisis in the innovation process (Lyon, 2017; Heinze, 2014); the 
identification of new opportunities (Hoyte, 2015); family startups (Jones \& Li, 2017); and the use of inductive thought in entrepreneurship (Cornelissen \& Clarke, 2017).

However, if each new mutation of capitalism brings with it new narratives (Sennet, 20117), it is worth further exploring how the concept relates to innovative entrepreneurs and dissecting their sernsemaking narrative during the startup innovation process. To close the gap that keeps us from understanding this process in depth, we aim to identify and explain the critical points of sensemaking from the perspective and the experience of startup entrepreneurs, based on the narrative of turning an idea into a market product. In so doing, we intend to:

(1) understand how progress is made through iterative validation and how uncertainties are identified and overcome;

(2) determine the practices employed to this end;

(3) advance our knowledge of entrepreneurs' sensemaking mechanisms.

When we understand the narratives, we understand the world view (Macintyre, 1981). Weick's approach to sensemaking is especially apt for organizations - that is, closed collectives that share certain hierarchical structures and institutional supraobjectives (Weick, 1995). We opt to follow Dervin's approach for the case in question, since it relates not to companies but to an informal ecosystem of persons who, through discontinuous interrelations, share the same contexts of uncertainty and face similar situations. Moreover, Dervin's sensemaking provides a metatheory that, based on the interiority of the agents, enables a holistic and practical approach to understanding the concept (Narayan \& Olsson, 2013). Derwin's conceptualization, unlike that of Weick, stresses the subjects/participants and not the organization, giving access, in a manner of speaking, to a particular experience. The researcher has the task of transcending individualities in order to structure the basic constituents and similarities of an open collective (Moore \& Hoffman, 2011).

From this theoretical and practical approach, sensemaking, as with innovation, is characterized by iteration in response to a vast world of which we have no more than fragmentary sense (Dervin, 2008; 1992). This sense, far from being static and definitive, undergoes constant construction and deconstruction (Dervin, 1992), because it depends on 1) those who produce (the sensemakers); and 2) the situations, bound to a space and a time, in which they produce (Foreman-Wernet, 2003).

In this space-time approach, individuals experience situations that they need to bestow with meaning (Dervin, 2003) and this meaning is discontinuous because it is constructed step-by-step (Dervin, 1983). Understanding the steps in which sense is created is of vital importance to the researcher (Dervin, 1983), for which the metaphor of the bridge, illustrated through the sensemaking triangle, is useful (Dervin, 2008; 1992) (Fig.1).

The basic concepts of this triangle are:

(1) the situation, understood as the specific epistemological space-time context where the individual must construct meaning (Dervin, 1983);

(2) the gap, which refers to the situational uncertainty that incapacitates the individual's actions, and which must be understood/overcome through sense; and

(3) the outcome, the action, and the objective of the individual (Dervin, 1992).

Thus, for Dervin $(2008 ; 2003 ; 1992)$ sense is constructed when the sensemaker identifies and then bridges the gap in a given situation until an outcome is achieved; from one end to another, it is this bridge build across the void that constitutes sense. 
Fig. 1 Dervin's sensemaking triangle

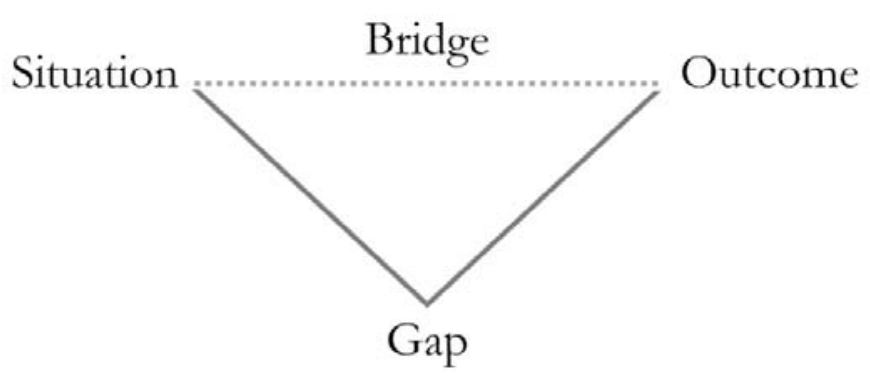

Source: compiled by author, based on Dervin $(2008,1992)$.

Dialogue is another notable component of Dervin's sensemaking. That is, the triangular process is not founded on unidirectional information transmission, but on overall interaction: dialogue (Dervin \& Foreman-Wernet, 2012). Dialogue means that sense flows from sharing experiences, discussing situations, and constructing together (Dervin \& Naumer, 2009); in sum, it is intersubjective (Narayan \& Olsson, 2013). And this dialogue has repercussions for the researcher's theoretical sensibility since, as Dervin points out: "the bottom-line goal of Sense-Making from its inception has been to find out what users - audiences, customers, patrons, employees - 'really' think, feel, want, dream" (Dervin, 1998) 39).

This practical framework and theoretical sensibility are employed in the sensemaking literature based on Dervin's approach, as they allow the concept to be transferred operationally to an exploratory methodology.

Entrepreneurs constantly face unprecedented situations and new gaps at every step; with Dervin's approach, it is possible to investigate how this search for sense is performed.

\section{Methodology}

We opt for a qualitative methodology, which is ideal for capturing, analyzing and understanding participant data (Yin, 2011) and is the most appropriate for process-based phenomena (Pettigrew, 1992). In the methodological design, we use the grounded theory proposed by Charmaz (2006).

Sample Our sample was made up of 43 entrepreneurs from 43 different Spanish startups pertaining to different industries. We limited ourselves to Spanish territory for methodological (ease of access to the entrepreneurs) as well as ecosystemic reasons (though their proposals had global aspirations, the startups and the other agents in the innovation economy share a local ecosystem, which predetermines and influences [Mazzucato, 201]). 
To select the startups, we prioritized those that had (1) attracted seed or growth investment; (2) participated in a bootcamp or incubator accelerator program; (3) been involved in a pilot test with a major company; and (4) received an award of some kind. These tend to be reliable filters in terms demonstrating the quality, robustness, and trajectory of a proposal in an ecosystem such as that of the startup, in which inflated expectations abound (Carayannis et al., 2018). For the interviews, we chose to speak with the CEO of each startup since, as Ries (2017) observes, out of the whole group these are the figures who tend to embody the deepest and broadest insight in terms of the innovative idea, technological expertise, and the history and future of the startup. As such, they make for ideal participants. Thus, we interviewed the CEOs of 43 startups from a total of 3,258 that were active in Spain during the period 2017-2018 (MWCB, 2018); this represents $1.3 \%$ coverage of the total. The entrepreneurs interviewed belonged to the following categories of startup, taken from the 12 categories in Startup Genome (2018) (Table 1):

Table 1 Description of sample by category

\begin{tabular}{|c|c|c|}
\hline Category & Description & Interviewees \\
\hline Biotech & $\begin{array}{l}\text { Biotechnological solutions (advanced genomics, mitochondrial } \\
\text { modification, hybridization, etc.) }\end{array}$ & 2 \\
\hline Health & $\begin{array}{l}\text { Health service transformation (digitalization, forecasting, } \\
\text { prescribing, etc.). }\end{array}$ & 3 \\
\hline Cleantech & $\begin{array}{l}\text { Green technological solutions for reducing environmental impact } \\
\text { (circular economy, renewable energy, etc.). }\end{array}$ & 5 \\
\hline $\begin{array}{c}\text { Artificial } \\
\text { Intelligence }\end{array}$ & $\begin{array}{l}\text { Development of solutions based on artificial intelligence and big } \\
\text { data (digital twins, text mining, chatbots, RPA, etc.) }\end{array}$ & 5 \\
\hline $\begin{array}{c}\text { Advance } \\
\text { Manufacturing }\end{array}$ & $\begin{array}{l}\text { Creation of new opportunities in Industry } 4.0 \text { alongside robotics } \\
\text { and cloud computing. }\end{array}$ & 3 \\
\hline $\begin{array}{l}\text { Agtech \& New } \\
\text { Food }\end{array}$ & $\begin{array}{l}\text { Disruptive solutions for the agricultural industry (remote sensing, } \\
\text { drones, smart metering, etc.) }\end{array}$ & 4 \\
\hline Edtech & $\begin{array}{l}\text { Development of technologies for education (customized } \\
\text { teaching, social learning, open source, etc.) }\end{array}$ & 1 \\
\hline $\begin{array}{l}\text { Fintech \& } \\
\text { Insurtech }\end{array}$ & $\begin{array}{l}\text { Integration of new technologies and business models to disrupt } \\
\text { banking (fin-) and insurance (insur-). }\end{array}$ & 6 \\
\hline Cybersecurity & $\begin{array}{l}\text { Data protection technologies in internet of things environments } \\
\text { (fog computing, cloud computing, etc.) }\end{array}$ & 6 \\
\hline Digital Media & $\begin{array}{l}\text { Content creation using new channels (LinkedIn, Facebook, } \\
\text { Twitter, Instagram, etc.) }\end{array}$ & 2 \\
\hline Adtech & $\begin{array}{l}\text { Advanced digital and analytical tools oriented toward } \\
\text { transforming the advertising industry. }\end{array}$ & 2 \\
\hline Gaming & $\begin{array}{l}\text { New ways of interacting with customers through games for } \\
\text { smartphones. }\end{array}$ & 4 \\
\hline
\end{tabular}

As to geography, $39.5 \%$ (17) of the startups in our sample were located in Barcelona; $37.2 \%$ (16) in Madrid; 7.0\% (3) in Bilbao; 9.3\% (4) in Valencia, 4.7\% (2) in Málaga; and $2.3 \%(1)$ in Vigo.

To complete our characterization of the sample, we present the stage of maturity of each startup at the time of our interviews with the corresponding entrepreneurs; for this, we availed of the Ernst\&Young (2013) classification (Table 2): 
Table 2. Description of sample by stage of maturity

\begin{tabular}{|c|c|c|}
\hline Stage & Description & Interviewees \\
\hline Pre-Seed & $\begin{array}{l}\text { Very early stage in which an idea is in place and possible business } \\
\text { models are explored through the search for inferences regarding } \\
\text { their viability. }\end{array}$ & 2 \\
\hline Seed & $\begin{array}{l}\text { After attracting the initial capital for the idea, testing is conducted } \\
\text { to provide a better appraisal of its business potential. Critical stage } \\
\text { in which the valley of death must be traversed. }\end{array}$ & 14 \\
\hline Start-up & $\begin{array}{l}\text { Practical exploration stage in which customers are sought and an } \\
\text { innovative solution is tested in order to verify economic stability. }\end{array}$ & 15 \\
\hline $\begin{array}{l}\text { Emerging } \\
\text { Growth }\end{array}$ & $\begin{array}{l}\text { Given evidence of economic sustainability, the startup focuses on } \\
\text { market exploitation of its proposal in order to upscale the venture } \\
\text { and the niche in terms of ambition and magnitude. }\end{array}$ & 9 \\
\hline Expansion & $\begin{array}{l}\text { The startup becomes a competitive company with a business } \\
\text { niche and a portfolio. }\end{array}$ & 3 \\
\hline
\end{tabular}

Source: compiled by author.

Data capture. We distinguish between primary and secondary sources (Charmaz, 2006).

The primary sources were twofold: practical information gathered directly from the field, and information stored in other media.

The practical knowledge came from our semistructured interviews with 43 entrepreneurs between June 2016 and February 2018. We contacted these interviews at specialized fairs, (such as 4 Years from Now), conferences, talks, conventions, summits and similar events in Spain; and online, via LinkedIn and e-mails. In both cases we proceeded in the same way: by explaining the research to the potential participant, asking them to participate and, if they accepted, conducting the interview in situ or scheduling it for a suitable date. Interviews were the most effective method for discerning the participants' points of view and the private meanings that mold their personal narratives (Charmaz, 2006); we interview because there is a real interest in the other, in their lived experience (Seidman, 2006).

As stated in the sample subsection, the participants met the necessary requirements (Weiss, 1995): (1) they possessed expert knowledge; and (2) the object of study was applicable to them. To this we added a third condition to assure the representativeness of the sample and future extrapolation (Seidman, 2006): that the participants represent different ages (between 19 and 57); forms of know-how (sociologists, MBAs, computer engineers, etc.); technologies (artificial intelligence, big data, augmented reality, graphene, blockchain, etc.); business models (freemium, sourcing, subscription, direct sales, bricks \& clicks, etc.) and industries (agriculture, banking, tourism, etc.) The interviews ranged from 29 to 92 minutes in length; 37 were in-person (either at an event or on their premises) and six were by Skype.

We assumed the dictum of listen more, talk less (Seidman, 2006: 78); as such, our role was to build a safe environment for communication, help the participants to explore their personal experiences, and guide the interview toward the research topics (Dervin, 2008; Charmaz, 2006) with minimal intrusion (Dervin, 2008); in this way, we steered clear of mechanical or vague responses that might have distorted the data (Seidman, 2006). As Dervin (2008) advised with the sensemaking triangle, interviews are directed through non-open questions and not forcibly standardized, with space given to the interviewees 
to explain their individual experience of the narration to be identified; in our case, at certain times we delved into aspects of the narration by drawing upon the guiding questions of Dervin \& Foreman-Wernet (2012): we proposed questions that allowed the interviewees could describe the microsituation they faced (situation), the location of the problem (gap), how they resolved it (bridge) and what the result was (outcome). Meanwhile, the interviewer's questions modulate the way in which the experience is narrated, in a process of joint reflection that allow the experience to be discerned in greater depth. In sensemaking, we are interested in the perspective of the participant the sensemaker - rather than the researcher (Dervin, 1992).

Our second type of primary sources were different types of data that served to cover knowledge caps and increase cognitive saturation of the participants' context (Yin, 2011): namely, information about the participants, from LinkedIn, Twitter and Instagram profiles; and content about the startups, from websites, videos, reports, PowerPoints, etc. In parallel, we also kept private fieldnotes in which we recorded information that, though unstructured, was nonetheless useful for reflecting and developing first intuitions (Emerson, 1995).

As far as secondary sources are concerned, we relied upon an extensive bibliographical review. As an essential source of knowledge, (Yin, 2011), we conducted a state of the art of sensemaking, and its application to entrepreneurs, startups and methodologies; then, we created our conceptual knowledge (Charmaz, 2006).

In grounded theory, links and feedback are established between live and bibliographical data (Charmaz, 2006), so efforts are multiplied through the constant communication between them.

We carried out this data capture until reaching theoretical saturation (Charmaz, 2006), which occurred in February 2018.

Analysis. To convert the data into evidence (Yin, 2011) we employed grounded theory, which offers a method of systematic structuring (Charmaz, 2016). Between January and February 2018, we transcribed 23 of the 43 the interviews, pertaining to those participants who had agreed to their interviews being recorded by smartphone. In the case of the remaining participants, we utilized the copious notes and verbatim quotes written down during the interviews. From February to May we coded the data collected from the different sources and, as we reviewed, compared, interpreted, and linked the data, constructed successive versions of code to connect the theory with the data. To consolidate the interpretive robustness and its validity, we combine the manual coding with Atlas. Ti v8. As an output of this intensive, iterative, and abductive process (Yin, 2011), the tenth coding provided a theoretical framework with which to explain the phenomenon studied.

\section{Results and discussion}

The application of Dervin's sensemaking $(1992 ; 2008)$ to focus on the experience of the participant - not representing any collective - and the microsituations that comprise that experience (what was the context? what was the obstacle? what did you feel? what did 
you do?) allowed us to identify individual lifelines and suggest a personal narrative which, interlinked with the successive coding mechanisms of grounded theory, patternsearching, and theoretical crystallization, result in a collective sensemaking narrative for the startup entrepreneurs. Having coded the data from the primary and secondary sources, we proceeded to create a relational suprastructure between them; the different versions, progressively refined through coding, display the first patterns, present in concepts or statements, which in turn allow theory to be forged from the phenomenal reality (Charmaz, 2016). This resulting narrative captures and represents the participants' perception and experience in the ideation, development, and validation of their innovative proposals. We define four stages, and identify three gaps (Fig. 2).

Fig. 2 Sensemaking narrative of the startup entrepreneurs

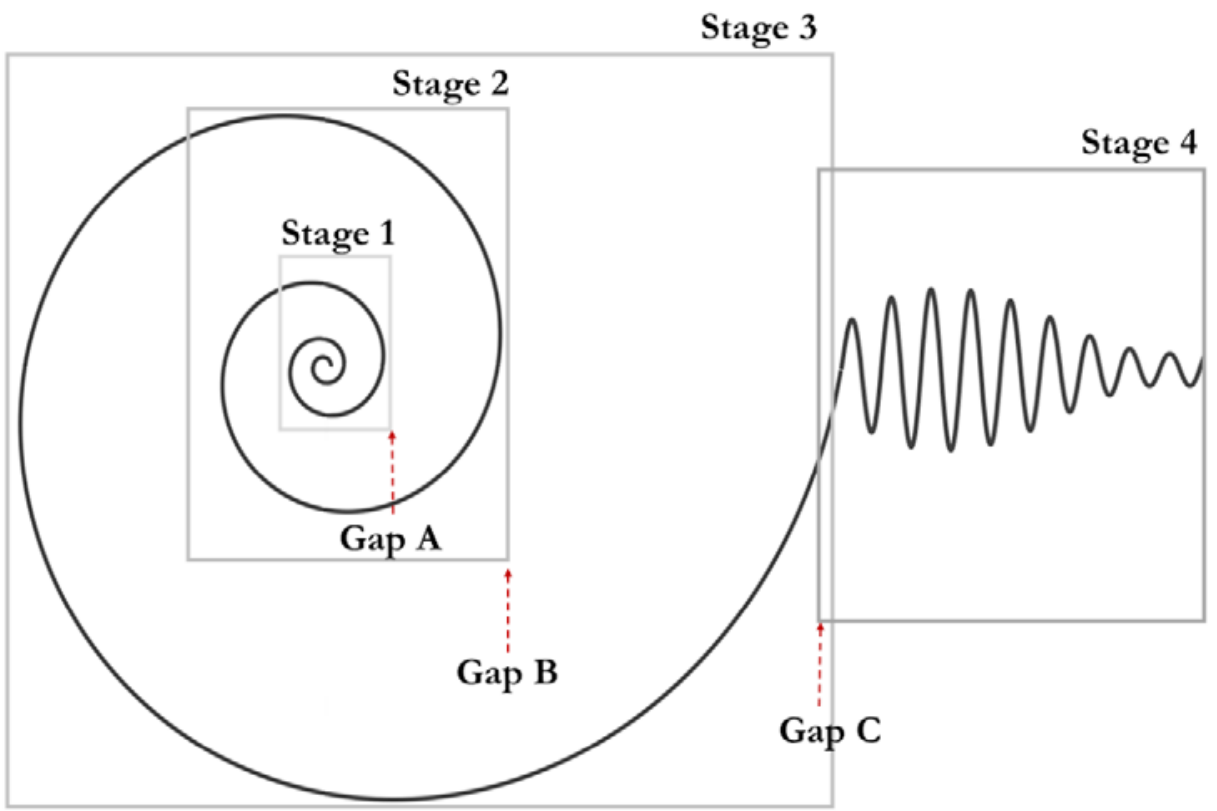

Source: compiled by author.

Below, we present the entrepreneurs' sensemaking narrative that emerged from our work based on grounded theory. The sensemaking narrative is the suprastructure (Level 1), which we segmented into four stages and three different gaps (Level 2), and, in turn, into the concepts contained in each stage and gap (Level 3). In Level 1, we also included the value shared between the entrepreneurs, which we call open perseverance.

Thus, we established three levels of detail emanating directly from the data analysis, allowing the sensemaking narrative to be explained with different degrees of detail (Table 3). 
Table 3: Coding structure

\begin{tabular}{|c|c|c|}
\hline Level 1 & Level 2 & Level 3 \\
\hline \multirow{7}{*}{$\begin{array}{c}\text { Sensemaking } \\
\text { narrative of the } \\
\text { startup } \\
\text { entrepreneurs } \\
\text { (open } \\
\text { perseverance) }\end{array}$} & $\begin{array}{l}\text { Stage } 1 \\
\text { Create }\end{array}$ & $\begin{array}{l}\text { \#Routes } \\
\text { \#Nuances } \\
\text { \#Limits } \\
\text { \#Coordinates } \\
\text { \#Internal logic } \\
\end{array}$ \\
\hline & Gap A & $\begin{array}{l}\text { \#Litmus Test } 1 \\
\text { \#Orientation } \\
\text { \#Desirability and Viability } \\
\text { \#Feedback }\end{array}$ \\
\hline & $\begin{array}{l}\text { Stage } 2 \\
\text { Define }\end{array}$ & $\begin{array}{l}\text { \#Integration } \\
\text { \#Systematic Logic } \\
\text { \#Fit } \\
\text { \#Sustainability } \\
\text { \#Attraction } \\
\end{array}$ \\
\hline & Gap B & $\begin{array}{l}\text { \#Survival } \\
\text { \#Involvement } \\
\text { \#Real Support } \\
\text { \#Development Hell 1 } \\
\end{array}$ \\
\hline & $\begin{array}{c}\text { Stage } 3 \\
\text { Develop }\end{array}$ & $\begin{array}{l}\text { \#Expectation } \\
\text { \#Focus } \\
\text { \#Bottleneck } \\
\text { \#Backing } \\
\end{array}$ \\
\hline & Gap C & $\begin{array}{l}\text { \#Overall Logic } \\
\text { \#Binding Decision } \\
\text { \#Litmus Test } 2 \\
\text { \#Development Hell } 2 \\
\end{array}$ \\
\hline & $\begin{array}{c}\text { Stage } 4 \\
\text { Consolidate }\end{array}$ & $\begin{array}{l}\text { \#Turbulences } \\
\text { \#Stability } \\
\text { \#Returns } \\
\text { \#Scalability } \\
\text { \#Growth }\end{array}$ \\
\hline
\end{tabular}

Source: compiled by author.

Qualitative data, in the view of Agar (1996), must be accompanied by an explanation, since such data cannot be removed from their space-time contexts; explanatory power lies in the interrelation between experiential data and their resulting collective eloquence. Thus, as in other qualitative studies, particularly ethnographic ones, we present the outcome and the discussion together, interlinked with the resultant sensemaking narrative. Moreover, since confidentiality and anonymity are fundamental in qualitative studies (Wiles et al., 2008), we agreed with the participants to remove their names, identifying them instead by " $1,2, \ldots, 43$ ", and by gender, age, startup reference, and other relevant characteristics.

\section{Stage 1. Creating}

For all of the individual narratives, the starting point was the initial idea: a brief and very simple concept that emerged, according to the entrepreneurs, along one of the following routes:

a. A desire to solve a specific problem (problem-solving approach): "When I saw my grandfather get disoriented, I had an idea." (11);

b. A desire to take an innovative business idea from another country and replicate it in Spain (cut-and-paste approach): "In Singapore it was all the rage. Why not here?" (7);

c. An intention to substitute an obsolete business model (substitution approach): "It's not possible to provide electricity in the way we've been doing up till now" (32);

d. An aspiration to explore a disruptive technology (technology-push approach): "We can optimize it with blockchain" (2);

e. Emergence of a new demand (market pull approach): "The millennials don't want it like that" (40). 
However, an idea alone is insufficient. For 42 of the participants, an idea is worth nothing, because: "[...] the trick is to develop it, to realize it " (43). To elaborate on the concept related to the idea, a stage of reflection needs to be opened between the entrepreneur and their team; and the idea only makes sense when nuances are added: "To begin with I saw it as a block. Something unitary. Very simple. I forced myself to look at the details" (18). The lack of definition of an idea was due to a lack of initial knowledge of the business model, the market niche, or the implications of the technology: three areas of knowledge that need to be well-established come the later stages. The mechanisms used by the entrepreneurs to make sense tended to involve standard innovation techniques: techniques for the conceptual exploration of the idea (for example, brainstorming); and to conceptualize it, consultation of specialized reports (for example, McKinsey or Trendwatching). As such, the idea grew along with the sense, connected to a context and based on personal hypotheses and assumptions.

The next step, increasing the complexity of the idea, meant examining its business implications; to this end, 31 of the participants cited the Business Model Canvas as a sensemaking mechanism: "It's simple. It helped me see the derivatives of the idea. It helped me reflect and change things" (22). At this point, the participants did not seek any longer to nourish the idea, but to establish its limits, structured around a business and an overview; thus, the entrepreneurs constructed a small system of coordinates to orient themselves: "When I started I thought everything was possible. But I forced myself to have a very vague notion of where I wanted to go. At least a guide" (7). Some of the participants (10) complained about the lack of information they had to begin with; others (23) about an oversaturation of information; but most (35) agreed on the need to have an order, even in the knowledge that new changes would later have to be made. This internal logic was achieved through iteration: "[...] I took two steps forward and then three steps back. With tenacity you end up with something that lasts" (29); and, in consequence, the idea underwent revisions.

Up to this point, the entrepreneurs built a sense that they knew to be unstable - it wasn't even yet meta-stable -but, in light of the information interpreted, it was possessed of a certain internal logic, sufficient for pondering the hypothetical value of their idea. The big initial uncertainties (what is the objective of my idea? Is there interest, etc.) dissipated, at least for the moment.

\section{Gap A}

For the continued construction of sense, a new, still-more concrete sensemaking mechanism was needed: testing and/or presenting the idea. "I loved my idea, seriously. The details fitted together. But I didn't know whether it made much sense with all the innovation that's out there. So the first important litmus test is to show it to others who aren't on the project" (28). That is, the entrepreneurs required external orientation to determine whether the internal logic of their idea had certain validity in a broader context, or whether there was a need to iterate it again and introduce drastic changes. Without this validation, it would have been impossible for them to continue with the sensemaking process. In the language of Weick (1995), they required knowledge peripheral to their experience in order to make sense. These internal impressions could either be used to present the idea to experts (gurus, investors, innovation specialists, other entrepreneurs) or to conduct testing (pretotypes or paper prototypes) with known or hypothetical users. Since these opinions were not bound to nor binding upon direct investment, most took the form of conceptual or practical guidance. Principally, this external orientation was needed to make progress, as the entrepreneurs had encountered two uncertainties that, on the face of it, were insurmountable. The first was the idea's hypothetical market potential: "I had to show off my idea." I didn't know if anyone would pay for it" (4); and the second, its technical feasibility: "I had no idea if what I was proposing could be done 
with the available technology" (30). As seen, in Gap A, the entrepreneurs became aware of two of the three variables from the viability triad: desirability and technological viability. Though they did not resolve these issues entirely at this point, they were able to obtain a degree of sense that allowed them to advance: "The feedback was very good. They found three or four details, that I had to rethink" (11). The encounter with new contexts and actors invariably made sense (Dervin, 2002).

During this first major sense gap, 26 of the entrepreneurs sought to obtain multiple inputs, as difficult as it may have been to reconcile different viewpoints, because this information served to renew their perspective of the idea: "With all the information I got, I managed to improve my idea a lot. I saw it with different eyes" (8). It was not easy for them to interpret the information and extract unitary sense, but the experience did compel them to look closer at the idea and improve their understanding of it. "I think when they tore me apart, the idea was good. For me it was worthwhile. I picked myself up, and I knew what I wanted to do with the data analytics" (15).

This external, guiding feedback allowed the entrepreneurs to overcome the first major gap and produced the first reflexive curve: an operation they would have to complete over successive stages and iterations.

\section{Stage 2. Defining}

The integration of the guiding feedback allowed the entrepreneurs to improve the internal logic of their idea and initiate new iterations in search of a new, more solid and stable sense; by interpreting these signals they persisted with the characteristics of their idea, in terms of both its weaknesses and its strengths, and in so doing turned it into a business. Participant 6 summed this up succinctly: "Here, things became more serious, because I had to tie together all the details. I couldn't let anything escape me. Before I could get away with having a few points in my proposal that I didn't know, that I doubted. But now, if I wanted it to become reality, I had to believe in it and justify it without hesitation" (6). From this response, it can be discerned that not only were the entrepreneurs expected to integrate the external feedback into their innovation proposals, but this feedback was to give rise to a systematic logic; that is, an overall connection between all of the elements that comprised the proposal. The sensemakers became aware of the need for the other - aware of the social dimension of sensemaking (Weick, 1995).

In the construction of sense, the entrepreneurs distanced themselves from the denomination "idea" to use other terms of greater semantic elevation. "opportunity", "value proposition", "innovation proposal" or "innovation".

However, the interpretation, integration and search for a systematic logic was not straight-forward; the iterations occurred because they had to, and 28 of the entrepreneurs expressed as much, resulting in a proposal where "[...] all the pieces fitted together" (1). This fit is not at all easy to achieve, because when the entrepreneurs introduced changes to their proposal with the aim of addressing doubts, others arose that they then had not previously considered. As a consequence: "The initial idea was nothing like the final one" [laughs] (20).

At Stage 2, the entrepreneurs also started to take into account the third variable in the triad: business sustainability, at least in the short term. This sustainability was understood in two senses:

a. practical, because by this point the startups required injections of funding to assure their exploration; and

b. conceptual, because they had to define the best business model for their proposal to ensure, in theory, the startup's survival. 
Both of these senses were critical to the continuity of the startups. "I was very enthusiastic, but after three months I couldn't live on air alone" (9). The way forward, according to 31 of the participants, lay in attracting capital, and to this end the entrepreneurs began to promote their proposal at different forums: "I presented $[X$, their startup] at all the events I could. They had to get to know you" (22). They also worked on improving their business model: "We looked to leave behind the traditional. We wanted to create blue oceans that would be profitable in three years" (10).

Thus, the second obstacle in the creation of sense lay in managing to attract investors' interest and capital; without this attraction, "[...] the adventure could not continue" (32).

\section{Gap B}

The sense around the innovation proposal should address the uncertainty of survival, one of the greatest obstacles. "This is a huge leap. Many good proposals perish here because they don't know how to demonstrate that there is continuity beyond the first idea" (9). The entrepreneurs perceived this sense gap as a "barrier", "a wall", or "a leap into the unknown". At this point they redoubled their efforts to promote their proposal and attract investment: "I didn't know where I would sleep. In Bilbao, Madrid, I presented it wherever I could" (16); "I think we presented at all the insurtech accelerators in Spain" (34).

If in the first gap the feedback was guiding and non-binding, here the external approval entailed a commitment to invest, or, in other words, serious involvement in the proposal, real support: "Everyone has opinions, but not money" [laughs] (12). Having reached this point, at which the sense regarding their proposal had matured, the entrepreneurs looked to give assurances that their proposal could have real continuity: "Not $100 \%$, but $70 \%$ yes" (2). Securing investment was very tough because "[...] There are very good people The competition is total. The investors want to know all the details. They don't like nonsense. Nor risks" (41); "Though there are plenty of daddy's boys playing at being an entrepreneur, only those who stake a lot, win" (39). Thus, the sense regarding the proposal had to be raised: "If you want someone to back your dream, you have to give them assurances" (37).

Here, two paths opened up. In the case of those who managed to convince investors or business angels, their proposal was subjected to one of the different forms of startup support with varying degrees of involvement: contest, award, coaching, mentoring, incubator, project, bootcamp, accelerator, co-development, etc. This real support was experienced by the entrepreneurs in a very positive way: "It is a huge moment when someone else believes in you" (7). According to Dervin \& Naumer (2009) certain forms of support, at certain times, reinforce the sense; in this case, real support, as a sensemaking mechanism, allowed the entrepreneurs to increase the complexity of their proposal and their ambition.

Those, on the other hand, who did not manage to convince investors had to go back to reflecting and iterating their proposal several times. They ran the risk of entering development hell, in which entrepreneurs are unable to make the valid sense required to advance in the definition of their proposal: "I thought it over a thousand times. Always about the same. You present, they reject you, you iterate, it feels like you're going nowhere" (10).

At the time of the interviews, 36 had to overcome this gap and seven were still working on it, tweaking details and trying their luck with external support. 
Morente, F. \& Ferràs, X. (2018) Open perseverance: the sensemaking narrative of startup entrepreneurs. Journal of Business, Universidad del Pacífico (Lima, Peru) Vol.10(2): 2-23

\section{Stage 3. Developing}

Reaching Stage 3 represented a "high" (8), a "joy" (26) for the entrepreneurs, given the feeling of security that came with the sense of having built something through effort, and, above all, the rise in expectations: "When they supported me, I felt that everything made sense. That all the effort was worth something. Someone backs you. You get excited. You feel a bit surer of what you are doing. You know there will be hard work ahead, that there is still a lot to be done, but you feel less insecure, less alone" (4). Of the participants, 19 stated that their expectations of success increased, because they felt more secure: "It's an injection of security" (1), "In a certain way you professionalize" (16), and "I felt I was going in the right direction" (29).

Thus, with this security now included in the sense, the entrepreneurs used the viability triad to concentrate on very specific aspects of their value proposition. "It didn't mean changing everything, like before. Now you had to focus on more specific things. Not many but vitally important. That was the difference" (34). Sensemaking goes through a narrow passage where possibilities are lost but uncertainties are smoothed over (Dervin, 2003). With certain parts of their proposal now assured, the crux lay in reducing the uncertainties associated with aspects that impeded progress: the bottlenecks. To resolve these, the entrepreneurs had to search for specific, high-quality inputs. The 36 entrepreneurs agreed that during the development of their proposals, in terms of both the business conceptualization and the prototype, they needed to limit and ration the external information; not all possessed the same value, and poor information could distort the sensemaking. At this point the entrepreneurs selected information aimed only at addressing their bottlenecks. "Screen it, yes. Every last opinion or what you see on the internet counts for nothing. Only [the information] that adds something matters" (22). Otherwise: "You lose focus. You lose time. You don't make progress" (5).

Throughout the focusing and prioritization of inputs, sense is made tacitly and explicitly in the swing from the individual to the social (Choo, 2002). The entrepreneurs felt externally supported, which could be beneficial or coactive in the sensemaking process. Despite the resource limitations - not only in terms of the entrepreneurs' time, but also of third-party capital of engagement - conditions became more demanding. From a positive perspective: "Whether the guidelines for progress came from outside or from experts, it made me feel more secure. Things went more quickly and I didn't get lost in minor details. They always pressurized you with the time, which is very exact, very limited, but in general having outside opinions was a very good experience" (4). In excess, these guidelines, security, times and opinions could be perceived as negatives: "There were days when I thought I was just another worker, that this wasn't my idea. Everyone had an opinion. I didn't know how to deal with that" (5). As such, backing was perceived as either very positive (4), positive (21), coactive (9), or intrusive (2).

Another fundamental mechanism in obtaining inputs, of especial significance for its sensemaking value, was the testing. The product of intense reflection and efforts, prototypes allowed the entrepreneurs to put their sensemaking progress to the test: "As the users have contact with your proposal, what they tell you has value, it's guided, it's useful to you" (3). The information obtained during the testing was much more reliable because it was an opportunity in which potential users could experience a first version of the proposal. Negative feedback was also perceived as a positive because it allowed weaknesses to be tackled: "They ripped the prototype apart. But without that damn awful afternoon, I wouldn't be here today" (41).

This stage ends once all entrepreneurs have a minimum viable product (MVP). Thus, the sense is turned onto something material. 
Morente, F. \& Ferràs, X. (2018) Open perseverance: the sensemaking narrative of startup entrepreneurs. Journal of Business, Universidad del Pacífico (Lima, Peru) Vol.10(2): 2-23

\section{Gap C}

For the entrepreneurs, going to market is an enormous leap that not everyone can make (Blank \& Dorf, 2012); thus, in our representation of the sensemaking narrative (Figure 2), it is the last big curve.

Before attempting to bridge Gap C and going to market, the entrepreneurs had managed to create stable, detailed and perfectly contextualized knowledge of their value proposition: "You can't aim to launch on the market with doubts. At this point, you know your innovation better than you know yourself." (11). This did not mean acquiring an internal or systematic logic, but going one step beyond: a total logic in which the three variables of the viability triad were, a priori, resolved through real arguments. The sense acquired up to this point came of the uninterrupted action of understanding; as Dervin (1992) suggests, the past and the present combine in action that anticipates the future. To leave behind the testing and iterations based on controlled risk and access the market, the entrepreneurs again needed to turn to binding external decisions: investors who would back their proposal and invest capital or let them use their market access channels. "Here I realized that my startup was something small. Very promising, but small. And if I wanted to carry on, I needed to convince investors to be able to go to market" (37). Most entrepreneurs carefully prepared a pitch in which they presented their prior experience, arguments for investing, and business growth expectations. The capital sums were very high and, thus, so too were the risks assumed. "You can't ignore them, or they get anxious. You make promises, but with sound basis" (27). It was also crucial: "[...] to believe $300 \%$ in your proposal. If you don't believe in it, it's obvious. And if it's obvious, they don't back you. You don't triumph" (2). The situation was experienced by the entrepreneurs with a good deal of stress, as a second litmus test, and, thus, any mistake could bring their work to a halt: "It's not a hobby any longer. You're talking about significant sums" (11); "They don't give you their opinion any more. If you mess it up, they turn their back on you,it's over (31).

If the entrepreneurs managed to convince of the future scalability of their business proposal, it generated a feeling of euphoria: "One of the happiest days of my life" (2), "A moral reward" (34), with an impression of "[...] negotiating the final barrier to the market" (25). Otherwise, they ran the risk of a second development hell, rendered all the more infernal and grim when associated with the depletion of resources of time, finances, and enthusiasm; project development would become circular and sterile while a practical way out was awaited: "Here there are no problems, just crises" (20). Some of the entrepreneurs abandoned their proposal (6), others tried to iterate it (7) and still others harbored doubts about how to go on (5).

At the time of the interviews, of the 36 entrepreneurs who had overcome Gap B, 18 had accessed the market.

\section{Stage 4. Consolidating}

The previous steps are regarded as the gestation (Tidd \& Bessant, 2011), since the life of the entrepreneur begins with the turbulences of the market (Ries, 2011).

The 18 entrepreneurs who accessed the market had sensemaking narratives not without setbacks, but linear nonetheless. "I'm not lurching. It's no longer a case of big iterations where you change everything. Now I'm looking toward the stability of the product" (34). Thus, the sense entailed the pursuit of stability despite the turbulences. "When I launched the product, I expected a certain response from the millennials, but it ended up being the opposite. I had to adjust the marketing and the look and feel of the app" (11). At this stage the great uncertainty was "[...] how the market would respond" (18). To make sense that would give them stability, most of the entrepreneurs (16) employed a market response-adjustment binomial. In response to market turbulence, a new adjustment would be required. Assuring the product, improving the robustness of the 
service, increasing market share, etc. were some of the concerns associated with achieving stability. Of the entrepreneurs, seven referred to this as "pivoting". The notion of stability was summarized in the phrase of entrepreneur 34:"Now you have to be a practical, dreamer" (34). Sense comes from the certainties acquired, giving the sensemakers a secure base (Dervin \& Foreman-Wernet, 2012)

The entrepreneurs were no longer exploring a sense, but exploiting it for commercial ends. The aim, for them, was to start to obtain returns: "I don't mean intangible returns, like image, reputation and all that, But tangible ones: money" (5). Appearing in the media was perceived as something positive, but the entrepreneurs had to bear in mind that "[...] you need to generate financial returns to reinvent, grow" (11). An influx of returns meant that investors could be placated, and greater scalability proposed for the startup. Without returns, the startups could not be sustainable over time.

Once they had a sense of security, ratified by returns "[...] they are the best market responses" (5), the entrepreneurs proposed scalability based on two different strategies:

a. advancing in understanding and exploiting the market microniche by enhancing the offering (vertical scalability); or

b. transferring knowledge to other microniches through new product attributes (horiontal scalability).

The purpose of the two strategies is to foster the startup's growth: "The idea is not for us to be four people, but to become bigger" (11). Both strategies denote what Weick (1995) terms the exportation of sense: an unequivocal sign of feeling in possession of a clear sense, which, after growing, seeks to convince. Transferred to the entrepreneurial works, the next chapter in the sensemaking narrative ends when the startup grows, is backed, becomes sustainable, acquires sufficient returns, and becomes a business, marking the beginning of a new narrative: the organizational one.

Throughout the entire sensemaking narrative presented here, we have identified one constant in the participants: a perpetuum mobile, a common value. In our coding, we call this new concept open perseverance. According to the Real Academia Española, 'perseverance', from the Latin perseverantia, is defined as "the act and effect of persevering"; to persevere, perseverare, is to "remain constant in pursuit of what has been started, in an attitude or an opinion", and "endure permanently or for a long time". As we found in the interviews, this is the value shared by all startup entrepreneurs; a sort of inner force that drives them forward despite the risks, uncertainties, and negatives. However, this has nothing to do with closed perseverance, confined to a fixed, selfsufficient idea; on the contrary, just like the sense that Chesbrough (2006) attributes to open innovation, entrepreneurs prove to be open, porous to the exterior, and ever-aware that resources stem from knowledge and that a considerable part of their idea's success depends greatly on agents external to them. This concept of open perseverance therefore unites (1) an internal force: the need for an internal logic in the idea itself, an obdurance in the entrepreneurs' horizon of attainment and in their capacities; with (2) an external influence: the need to be receptive to possible alliances with third parties and to peripheral knowledge. Properly directed, the entrepreneurs' internal force and the external influences of the startup ecosystem transform and reinforce the sense significance, direction - of the process of converting an idea into a product or service. Profound internal understanding is only obtained and enriched through continuous contact with the exterior; in this way, progress is made towards a metastable sense, subject to vicissitudes, prone to change but with solid foundations that respond to the viability triangle. The open perseverance of the startup entrepreneurs influences and evidences the eminently social nature of innovation, in which the individual and the 
collective are located in an understanding of the past that defines the steps into the future.

\section{Conclusions}

In new capitalism, the narratives of markets and personnel are indivisible; fluctuating, unstable, and shifting environments affect the workers (Sennett, 2007). With Dervin's microsituational approach, we have defined a four-stage sensemaking narrative for startup entrepreneurs, fraught with microgaps and three major gaps, to provide a characterization of how entrepreneurs make sense. We then concluded with reference to the value that draws together startup entrepreneurs: open perseverance. In the case of the narrative constructed here, we note that:

1. sensemaking is spiral (iterative and accumulative) in the first three stages and modular (rectilinear and turbulent) in the fourth;

2. Interpreting, integrating, and discarding information and sense is a way of acquiring experience and new forms of sense related to direction;

3. The search for sense, across several microgaps, becomes a progressive acquisition of confidence;

4. Error is not regarded as fatal but as a learning experience;

5. At gaps A, B, and C, the sense accumulated must be consolidated and verified in order to advance;

6. The complete sensemaking narrative is the result of a complex and tense socialization between the entrepreneur and external parties (users, investors etc.)

7. The entrepreneurs' lived experience is a positive narrative of personal growth and professional success;

8. In this final state, the entrepreneurs feel in possession of a sense that grants them autonomy; and

9. The startup entrepreneurs share the value of perseverance, which recognizes that individual efforts and knowledge are not sufficient for the creation of metastable sense; these entrepreneurs must secure, complete, and expand the sense of their innovative proposal through its integration into an external ecosystem.

Exceptions aside, the entrepreneurs' sensemaking narrative reveals an agile and overdimensioned startup ecosystem composed of the startups themselves, established companies, accelerators, incubators, and other economic and innovation actors, and characterized by speculation about expectations more than immediate tangible results. Exploring new business models about which no knowledge whatsoever is possessed, and the need to make sense quickly, brings to bear the capitalist dynamic of infinite market hypersegmentation in search of new blue oceans.

Our aim was to propose a sensemaking narrative and identify its primary milestones; however, future studies need to build upon our contribution by focusing on other considerations to enrich our knowledge of the "entrepreneur": economic (real impact of returns); sociological (personal growth vs integration into market structures); ecosystem (isomorphisms, as per DiMaggio and Powell, 1983); geographical (the close relationship between global ambitions and local environments); and labor (are entrepreneurs the future of work?). These suggestions are but some of the lines that could be pursued to continue making sense of entrepreneurs.

Possible limitations of this study are associated with the sample size (1.3\% coverage) and the shortcomings inherent to Dervin's methodology. We have attempted to address 
the former by introducing a variety of startup industries and stages of maturity. The latter is related to our aim of identifying individual narratives: a homogeneous, uniform questionnaire to 1,000 participants rather than 43 would not have served our purpose. In other words, the use of Dervin's sensemaking approach automatically confines research - if we aspire to rigor and ethics in the data - to small samples, from which we seek to fully extract all possible meaning and significance. For future studies, we recommend replicating Dervin's sensemaking for the same collective to establish increasingly broad comparisons that reflect a progressively clear and general narrative. Sense, ultimately, allows us to inhabit the world (Weick, 1995; Dervin, 1992).

\section{References}

Agar, M. (1996). The professional stranger. An informal introduction to ethnography. New York: Academic Press.

Alter, N. (2013). L'innovation ordinaire. Paris: PUF.

ASCRI (2007). Asociación Española de Capital, Crecimiento e Inversión - First Quarter 2018, in: https://www.ascri.org/wp-content/uploads/2018/05/NP-Congreso-ASCRI2018.pdf

Attfield, S.; Fields, B.; Wheat, A.; Hutton, R.; Nixon, J.; Leggatt, A.; \& Blackford, H. (2015). Distributed sensemaking: a case study of military analysis. ICNDM 2015, McLean.

Balogun, J. \& Johnson, G. (2004). Organizational restructuring and middle manager sensemaking. Academy of Management Journal, 47(4): 523-549.

Bessant, J. \&Tidd, J. (2011). Innovation and entrepreneurship. New York: Wiley.

Blank, S. \&Dorf, B. (2012). The startup owner's manual. The step by step guide for building a great company. New York: K\&S Ranch.

Carayannis, E.G.; Dagnino, G.B.; Alvarez, Sh.; \& Faraci, R. (2018). Entrepreneurial ecosystems and the diffusion of startups. Cheltenham: Edward Felgar.

Case, S. (2017). Third wave: an entrepreneur's vision of the future. New York: Simon + Schuster Inc.

Chan Kim, W. \& Mauborgne, R.A. (2014). Blue Ocean Strategy. How to create uncontested market space and make competition irrelevant. Harvard: Harvard Business Review Press.

Charmaz, K. (2006). Constructing grounded theory. A practical guide through qualitative analysis. London: Thousand Oaks.

Chesbrough, H.W. (2006). Open Innovation: researching a new paradigm. Oxford and New York: Oxford University Press.

Choo, C.W. (2002). Sensemaking, knowledge creation and decision making: organization knowing as emergent strategy, in Choo, C. W. \& Bontins, N. (eds.). The strategic management of intellectual capital and organizational knowledge. New York: Oxford University Press (157-178). 
Cornelissen, J.P. \& Clarke, J.S. (2017). Imagining and rationalizing opportunities. Inductive reasoning and the creation and justification of new ventures. Academy of Management Review. 35(4): 35-72.

Deakins, D. \& Whittman, G. (2000). Business startup. Theory, practice and policy, in: Carter, S. \& Jones-Evans, D. (eds.). Entreprise and Small business, practice and policy. London: Prentice Hall (115-131).

Dervin, B. (1983). An overview of sense-making research. Concepts, methods, and results to date. International Communication Association Annual Meeting, Dallas.

Dervin, B. (1992). From the mind's eye of the 'user': the sense-making qualitativequantitative methodology, in Glazer, J.D. y Powell, R.R. (eds.). Qualitative research in information management. Englewood: Libraries Unlimited (61-84).

Dervin, B. (1998). Sense-making theory and practice: an overview of user interests in knowledge and use. Journal of Knowledge Management, 2(2), 36-46.

Dervin, B. (2003). Chaos, order, and sensemaking: a proposed theory of information design, in Dervin, B. \& Foreman-Wernet, L. (eds.). Sense-Making Methodology reader: Selected writings of Brenda Dervin. Cresskill: Hampton (325-340).

Dervin, B. (2008) Interviewing as dialectical practice: sense-making methodology as exemplar. International Media and Communication Research (IAMCER) Meeting, Estocolmo.

Dervin, B. \& Foreman-Wernet, L. (2012). Sense-making methodology as an approach to understanding and designing for campaign audiences: a turn to communication communicatively, in Atkin, C. \& Rice, R.E. (eds.) Public Communication Campaigns. New York: Sage Publications (147-162).

Dervin, B. \& Naumer, C.M. (2009). Sense-making. In Encyclopedia of Library and Information Sciences. New York: Taylor and Francis.

DiMaggio, P.J. \& Powell, W.W. (1983). The iron cage revisited: institutional isomorphism and collective rationality in organizational fields. American Sociological Review, 48(2): 147-160.

Emerson, R.M. (1996). Writing ethnographic fieldnotes. Chicago: University of Chicago. Ernst\&Young (2013). Funding the future. Access to finance for entrepreneurs in the G20, in:https://www.ey.com/Publication/vwLUAssets/EY_G20_-

_Funding_the_future:/\$FILE/EY-g20-Funding-the-future.pdf

Feldbrugge, K. (2014). Making sense of the temporary organization in innovation: a case description. 28th IPMA Congress, Rotterdam.

Foreman-Wernet, L. (2003). Rethinking communication: Introducing the Sense-Making Methodology. Reprinted, in: Dervin, B. \& Foreman-Wernet, L. (Eds.). Sense-Making Methodology reader: Selected writings of Brenda Dervin. Cresskill: Hampton (3-16).

Gaglio, G. (2011). Sociologie de l'innovation. Paris: PUF.

Geersbro, J., \& Ritter, T. (2010). External performance barriers in business networks: Uncertainty, ambiguity, and conflict. Journal of Business \& Industrial Marketing, 25(3): 196-201. 
Gephart, R. P. (1997). Hazardous measures: An interpretive textual analysis of quantitative sensemaking during crises. Journal of Organizational Behavior, 18: 583622.

Heinze, I. (2014). Entrepreneur sensemaking of business failure. Small Enterprise Research. 20(1): 21-39.

Hoyte, C.A.S. (2015). Making sense of entrepreneurial opportunities. Doctoral thesis, University of Nottingham, Nottingham.

Hunsaker, T. \& Thomas, D.E. (2017). The viability triad. Desiderability, feasibility, and sustainability. Journal of Management Policies and Practices. 5(2): 1-4.

Jones, O. \& Li, H. (2017). Effectual entrepreneuring: sensemaking in a family-based start-up. Entrepreneurship \& Regional Development. March, 1-34.

Kelly, G. \& Morley, M.J. (2011). On the value of cognitive sense-making theory in modeling the dynamics of international executive repatriation, en: Benson, P.G. (ed.). Emerging themes in international management of human resources. New Mexico: Information Age (235-256).

Kitzmiller, R.R.; Anderson, R. \& McDaniel, R.R. Jr. (2010). Making sense of health information technology implementation. A qualitative study protocol. Implementation Science, 5, 2-8.

Lyon, S.J. (2017). Sensemaking in entrepreneurial ventures. Doctoral thesis, University of Warwick, Warwick.

Macintyre, A. (1981). After virtue. Indiana: University of Notre Dame Press.

Maitlis, S. (2005). The social processes of organizational sensemaking. Academy of Management Journal, 1(Feb): 21-49.

Maitlis, S. \& Christianson, M. (2014). Sensemaking in Organizations: taking stock and moving forward. Academy of Management Annals, 8(1): 57-125.

Marx, G.T. (2017). Windows into the soul. Surveillance and society in an age of high technology. Chicago: University of Chicago Press.

Mazzucato, M. (2018). The value of everything. Making and taking in the global economy. New York: Public Affairs.

Moore, D.T. \& Hoffman, R.R. (2011). Sensemaking: a transformative paradigm. American Intelligence, 29(1): 26-36.

MWCB (2018). Digital startup ecosystem overview, in: http://www.awex.es/sites/default/files/Mobile_World_Capital_Barcelona__Digital_Startup_Ecosystem_Overview_2018.pdf

Narayan, B. \& Olsson, M. (2013). Sense-making across space and time: implications for organization and findability of information. ASIST 2013, Montreal.

Nouri, P. \& Kafeshani, A.A. (2014). Sensemaking, a new entrepreneurial approach for today's uncertain business environment. IJAREMS. 3(6): 201-206 
Peneder, M. (2009). The Meaning of Entrepreneurship: A Modular Concept. WIFO Working Papers, № 335.

Pettigrew, A. (1992). The character and significance of strategy process research. Strategic Management Journal, 13, 5-16.

Pich, M.T., Loch, C.H. y Meyer, A. (2002). On uncertainty, ambiguity, and complexity in project management. Management Science, 48, 1008-1023.

Porter, M. E. (1980). Competitive strategy. New York: Free Press.

Ries, E. (2011). The Lean Startup. How today's entrepreneurs use continuous innovation to create radically successful businesses. New York: Crown Business.

Ries, E. (2017). The startup way. How modern companies use entrepreneurial management to transform culture and drive long growth. New York: Currency.

Sabino de Freitas, A. \& Bandeira-de-Melho, R. (2012). Managerial action and sensemaking in e-learning implementation in Brazilian business schools. Computers \& Education, 59, 1286-1299.

Sacks, H. (2006). Lectures on conversation. Volume I \& II. Edited by Gail Jefferson, with an Introduction by Emanuel A. Schegloff. Oxford: Blackwell.

Salhman, W.A.; Stevenson, H.H.; Roberts, M.J. \& Bhide, A.V. (1999). The entrepreneurial venture. Harvard: Harvard Business School Press.

Sarasvathy, S.D. (2008). Effectuation: Elements of entrepreneurial expertise. Cheltenham: Edward Elgar.

Schaper, M.; Volery, T., \& Weber, P. (2014). Entrepreneurship and Small Business. A Pacific Rim perspective. Milton: Wiley \& Sons.

Segger Macri Russo, R.F.; Sbraggia, R.; \& Sih Oih Yu, A. (2017). Unknown unknowns in innovative projects: early signs sensemaking. Brazilian Administration review, 14(3): 2-24.

Seidman, I. (2006). Interviewing as qualitative research. A guide for researchers in education and the social sciences. New York: Teachers College Press.

Sennett, R. (2007). The culture of the new capitalism. New York: Yale University Press. Shane, S. \& Venkatramana, S. (2000). The promise of entrepreneurship as a field of research. Academy of Management Review, 25(1): 217-226.

Sneddon, J. (2008). Innovation in the Australian wool industry: a sensemaking perspective, University of Western Australia, Perth.

Startup Genome (2018). Global startup ecosystem report 2018, in: https://startupgenome.com/reports/2018/GSER-2018-v1.1.pdf

Stiegler, B. (20015). La societé automatique 1. L'avenir du travail. Paris: Fayard.

Thiel, P. \& Masters, B. (2014). Zero to one. Notes on startups, or how to build the future. New York: Currency. 
Walls, J. (2017). Sensemaking and school failure: lessons from two cases. Journal of Organizational Theory in Education. 2, 1-26.

Weick, K. (1995). Sense-making in Organizations. London: Sage.

Weick, K.E.; Sutcliffe, K.M. \& Obstfeld, D. (2005). Organizing and the process of sensemaking. Organization Science, 16(4): 409-421.

Weiss, R.S. (1995). Learning from strangers. The art and method of qualitative interview studies. New York: Free Press.

Wickhman, P. (2004). Strategic entrepreneurship. Harlow: Prentice-Hall.

Wiles, R.; Crow, G.; Heath, S. \& Charles, V. (2008). The management of confidentiality and anonymity in social research. International Journal of Social Research Methodology, $11,417-428$.

Yin, R.K. (2011). Qualitative research from start to finish. New York: Guilford Press.

Zhang, P. \& Duohuai, G. (2014). Collective sensemaking in social media. A case study of the H7N9 Flu Pandemic in China. iConference 2014, Berlin. 